\title{
Health Impact of Climate Change and Air Quality
}

\author{
Ling-Ling Chen* and Chao-Heng Tseng \\ Institute of Environment Engineering and Management, National Taipei University of Technology, Taiwan
}

\begin{abstract}
The paper examines the relevance of the climate change adaptation and disaster reduction risk for supply chain processes in industry. Through a structured review of academic literature two primary challenges are highlighted: first, non-consistencymethod in integrating formal attribution of climate change adaptation and disaster reduction risk, and second in impacting with changing ecological environment and unpredictable natural disasters for supply chain processes in industry can be described as unavoidable. In examining these two challenges, we arrive at a climate change adaptation framework for industry supply chain as well as a framework of integratedclimate change adaptation and disaster reduction risk for industry cluster. In offering this viewpoint, related climate change adaptation and disaster reduction risk, acomprehensive risk and adaptation management approach is proposed as a practical framing for above two challenges to address climate change impacts and risks for supply chain processes in industry as well as promote the ability of risk and adaptation management in industrial operation process.
\end{abstract}

KEYWORDS: Climate change, Global warming, Air quality, Air pollutant, Human health, Extreme weather events, Health impact, Cardiovascular diseases, Respiratory system diseases, Cross-border

${ }^{\star}$ Correspondence to: Ling-Ling Chen, Institute of Environment Engineering and Management, National Taipei University of Technology 1, Sec. 3, Zhongxiao E. Rd., Taipei 10608, Taiwan, Tel: 886+ 227712171 \#4185; E-mail: amy@mail.ntut.edu.tw

Received: October 25, 2019; Accepted: November 07, 2019; Published: November 10, 2019

\section{Introduction}

Global warming and climate change, which have accompanied the advancement in science and technology, lead to changes in ecological environments and the exacerbation of extreme weather worldwide. These phenomena impose serious shocks on the living environment of humankind. The World Meteorological Organization (WMO) and the World Health Organization (WHO) convened a special meeting in 2012 and published the Atlas of Health and Climate jointly. They stated that to respond to global warming and climate change appropriately, governments need to establish services that help predict diseases and care for the disadvantaged and elderly. The conclusion of the 2014 United Nations Climate Summit mentioned that we can mitigate the possible impact and impact of climate change with the help of all parties involved worldwide in the future. The WHO also lists the health impacts of climate change as one of its top priorities. The WHO and WMO jointly launched the 'Heatwaves and Health Guidance on Warning-System Development' to provide more health services through continuous integration of climate-related issues and information.

In the 21 st century, human health has been severely affected by climate change [1]. The Inter governmental Panel on Climate Change (IPCC) proposed the Fifth Assessment Report (AR5) on Climate Change in 2014. This reportdivided the impact of climate change on human beings into direct and indirect shocks. Direct shocks are the cold/heat damage caused by the temperature and injuries sustained in accidents (e.g. increased mortality and morbidity) caused by drought, floods, heavy rainfall and other extreme events. On the basis ofa report by the WHO in 2012 titled ' 10 facts on climate change and health', it was estimated that extreme weather events such as heat waves, heavy rains and floods resulting from climate change could have caused about 600,000 deaths worldwide in the 1990s; the economic losses due to natural disasters from 2000 to 2009 were estimated as high as 8,900 USD based on the International Disaster Database (EM-DAT) [2]. Meanwhile, indirect shocks are mainly due to changes in temperature and rainfall, which affect the growth and distribution of organisms, or the generation of secondary air pollutants (such as ozone and aerosols), which affect the prevalence of respiratory and cardiovascular diseases. According to a study by the Institute for Health Metrics and Evaluation reported in The Lancet on 29 October 2017, about 9 million people died of air pollution in 2015; that is, 1 of the 6 dead in the world died of diseases caused by pollution of air, water, soil and working environment, and air pollution imposed a heavy burden on the global economy. It is estimated that the economic loss annually caused by air pollution amounts to 4.6 trillion U.S. dollars, accounting for $6.2 \%$ of the global economy [3].

This shows that climate change and air pollution actually shock and harm human health because there exists a relationship between the two factors. Climate change affects the local climate, rainfall patternsand sunshine hours and causes other changes, indirectly affecting the concentration of substancesin the air that are harmful to human health. The article will introduce the health shocks of climate change and air quality to provide reference for cross-border environment researchers and will clarify that the research fields of climate change, air quality and health do overlap but basic researchin each field is necessary. Exchange of information and knowledge will help these fields develop together in an ordered manner.

\section{Impacts of air quality on climate change}

Health impacts of climate change may arise from extreme temperatures (high or low temperatures), air pollution, floods, droughts and infectious diseases [4]. For fragile populations such as children, adolescents, persons with disabilities and the elderly, extreme 
weather events triggered by climate change may result inshortage of available resources, problems related to cognition and awareness of crisis, and weak response to climate change, and the risk of health hazards is higher for such populations. For example, for elderly people with cardiovascular diseases or chronic diseases, poor ability to respond to climate change results in faster contraction of diseases or worsening of the original disease and leads to a relative increase in morbidity and mortality. Another example is that if temperature rise causes the production of secondary air pollutants (such as ozone and aerosols), respiratory and cardiovascular disease treatment will be affected, leading to increased deaths.

Studies have shown that the most significant impact of climate change on air pollutants is with regard to ozone $[5,6]$. The concentration of ozone is influenced by economic development, energy use and local climatic conditions [7]. A study by the United States (U.S.) Environmental Protection Agency (2008) reported that an increase in the ozone concentration is highly possible owing to the climate change shocks in most parts of the U.S. Daily maximum ozone monitoring (for $8 \mathrm{~h} /$ day) in summer showed that the ozone value increased by 2-8 ppb. Under extreme climates, there is an increased chance of substantial rise in ozone concentration; however, the report also notes that the results of such studies are still subject to assumptions and the impact of space andconcentration of emissions. In addition, changes in meteorological conditions caused by rise in temperature also change the aerosol travel mechanism in the air because temperature will cause the indirect production of secondary particles, leading to increase or decrease in regional aerosol concentrations [8]. In Europe, a study on the shocks caused by climate change and local pollution discharge on Porto City in Portugal showed that as the urban temperature rises, air becomes dry, and the concentrations of ozone and aerosols increase; this will lead to poor air quality because of climate change shocks in 2046 and 2065 [9].

\section{Health impacts of climate change and air quality}

The National Institutes of Health have sorted out 14 relevant research papers about extreme temperature and health impacts during 2010 to 2016 for the U.S. and other countries. They found that the elderly population are indeed a high-risk group with regard to hightemperature situations in Taiwan and that cardiovascular, respiratory and other diseases and atmospheric temperature have a clear risk relation [10]. For example, patients with cardiovascular diseases are generally most likely to have the highest risk of dying on the highest temperature day during extremely high temperatures (greater than $31^{\circ} \mathrm{C}$ ) differences in day and night temperatures have a significant impact on population of age 65 years and more, and further, the effect on health conditions will be different for the different geographic locations and temperatures[11,12].

Kjellstrom et al. pointed out that climate change transfer and climate change have a negative impact on chronic diseases [13]. In short, the impact of climate change transfer will change the environmental conditions and produce corresponding events, resulting in health shocks. For example, humansexposed to an environment with heat waves may experienced ehydration, cardiovascular diseases, respiratory diseases, kidney diseases etc. and may suffer from an increased incidence of illness or death. Humansexposed to air pollution may suffer from cardiovascular diseases, respiratory diseases and asthma attacks and may experience an increased incidence of illness or death. In addition, the deaths caused by chronic diseases shows seasonal variations; this is especially so for cardiovascular diseases $[14,15]$.
Thus, with regard to climate change transfer shocks, temperature rise and extreme temperature events (such as heat waves) and interaction between climate change transfer and air pollution will affect human cardiovascular and respiratory diseases.

\section{Cardiovascular diseases}

Global temperature rise has adverse effects on the human body, causing problems such as myocardial infarction, ischaemic stroke and heart diseases. More importantly, this rise in temperature can even lead to death from various cardiovascular diseases [16-18].

Global extreme temperature events, such as extremely high/low temperatures, are occurring more frequently. Against this background, the international community has gradually begun to explore and assess the impact of the shock caused by extreme temperature events on health, but there is no unified standard or method to perform health impact assessment. In most studies, temperature percentage was used asthe classification standard. For example, the extreme high temperature has a defined range of $99.5,99,97,95$ and 90 percentiles and the extreme low temperatures are defined as the 1, 5 and 10 percentiles [19]. Chung et al. studied the association of extreme temperature events (extremely high temperatures and extremely low temperatures) in Taiwan with total cardiovascular disease from 1994 to 2007. They found that extremely high temperatures cause an immediate shockto human health, andthe extremely low temperatures cause delayed shocks to human health. Studies abroad mostly discuss the heat wave relation to total cardiovascular diseases: for example, the $1.86 \%$ increase in the risk of death from cardiovascular events in New Zealand from 1979 to 1997 [20]. From 1999 to 2010, during the heatwave incident in the U.S., related risk of treatment of heat stroke was 2.54 [21]. From 1979 and 2010, for four East Asian countries, the annual temperature differenceswere $6.4-12.6^{\circ} \mathrm{C}$; an increase of $1^{\circ} \mathrm{C}$ led to a $0.81 \%$ increase in the risk of death from total cardiovascular disease [12].

In addition, rise in temperature can lead to production of secondary air pollutants such as ozone and aerosols. Human exposure to air pollutants can cause a shock to their health. Hence, the interaction of climate change transfer (e.g. temperature) and air pollutants (e.g. ozone and aerosols) results in human health hazards (e.g. cardiovascular disease death) and creates health shocks (e.g. increased risk of dying). The increased mortality rate resulting from cardiovascular diseases has already been reported in related studies. For example, Li et al. examined theeffect of interaction between temperature and aerosols on total cardiovascular death in China from 2007 to 2009 [22]. They found that at high temperatures, exposure to aerosols will increase the risk of total cardiovascular disease by $0.92 \%$, and there also exists an interaction between the temperature and air pollution. Sario et al. studied the impact of interaction between heat/temperature and ozone/ aerosols on cardiovascular mortality in Europe from 1990 to 2004 [23]. The study results showed that heat/temperature and ozone/aerosols interact positively with cardiovascular disease death. Some Taiwanese research employing sub-data, such as national health insurance data, death registration, meteorological monitoring data of the Central Meteorological Bureau and air pollutants monitoring data of the EPD, dealt with the relation between climate and health. Forexample, Lin et al. studied the interaction between extremely high/low temperatures on cardiovascular disease death in the northern, central and southern metropolitan areas of Taiwan from 2000 to 2008 [22]. They found that at extremely high temperatures, the related risk of total cardiovascular disease death is 1.08 , where as it is 1.20 at extremely low temperatures.

\section{Respiratory system diseases}


Similar to cardiovascular system diseases, respiratory system diseases are also affected by the global temperature rise. The increased frequency of extreme weather events and interactions between meteorological conditions and air pollution affect human respiratory system diseases. For example, temperature rise leads to increase in death due to total cardiovascular system diseases and total respiratory system disease treatment. Chung et al. studied death by total respiratory system diseases in Taipei from 1994 to 2003; for every degree of rise in temperature, the death risk of total respiratory system diseases increased by $9.3 \%$ [16]. Lin et al. studied the situation of total respiratory illness treatment in New York City from 1991 to 2004; for every degree rise in temperature, the treatment risk of total respiratory illness increases by $2.7 \%$ [17]. Ostro et al. studied the total respiratory disease situation in California from 1999 to 2005; they found an increase of $0.50 \%$ in the risk of hospitalisation for total respiratory system diseases for every degreeof rise in temperature [18]. In addition, extreme temperature events and temperature differences can also lead to an increase in medical treatment for and death caused by total respiratory system diseases. For example, Huynen et al. studied the effects of heatwave events on the death due to total respiratory system diseases from 1979 to 1997 and found that the increased frequency of heat waves led to an increase of $12.82 \%$ in the risk of death due to total respiratory system diseases [20]. Chung et al. studied the impact of extreme temperature on thetotal respiratory system diseases in the U.S [16]. from 1992 to 2006 and found out that the risk of seeking medical attention for the total respiratory system diseases for humans increased by $4.3 \%$ under extreme temperatures.Kim et al. conducted a similar study covering four East Asian countries; they examined the impact of increase from $6.4^{\circ} \mathrm{C}$ to $12.6^{\circ} \mathrm{C}$ on the death due to total respiratory system diseases from 1979 to 2010 and found out that for every degree of rise in the temperature difference, the risk of death due to these diseases rose by $0.90 \%[12]$.

Climate factors and hazards due to air pollutantsexhibit interactions. In addition to increasing the risk of cardiovascular system diseases treatment and related death, shocks also lead to death due to asthma and respiratory diseases. Sheffield et al. studied the emergency situations related to asthma in the U.S [24]. under the climate change transfer between 1990 and 2020. They predict that ozone concentration will increase by $2.7-5.3 \mathrm{ppb}$ because of environmental change in the next 30 years and that the frequency of asthma emergencies will rise by $7.3 \%$. De Sario et al. studied the interaction between heat wave events and aerosols in Europe from 1990 to 2004 and deaths related to human respiratory system diseases [23]. They established that a positive association exists between heat waves and aerosols.

Studies conducted in Taiwan too have reported the interactions of rising temperature, extremely high/low temperature events, meteorological factors and air pollution with respiratory system diseases. These conditions will lead to total respiratory system diseases, lung obstruction, asthma, etc. and increase the frequency of related death and treatment. For example, Lin et al. studied the impact of extremely low temperature on total respiratory system diseases as reported in clinics between 2000 and 2008 in the northern, central and southern metropolitan areas of Taiwan [11]. They found that extremely low temperature on the cumulative relative risk of total respiratory system diseases clinic is $18 \%$ to $31 \%$. Tseng et al. studied theeffects of temperature changes on pulmonary obstruction in Taiwan from 1999 to 2009 and found out that the risk increased by $10.6 \%$ for every $5^{\circ} \mathrm{C}$ drop in temperature. Lin et al. studied the need for total respiratory system diseases treatment and asthma treatment under the interaction of air temperature and ozone in Taipei from 2000 to 2009 [11]. They found that the relative risk of treatment for total respiratory diseases under ozone exposure at low temperature was 1.10 and that for asthma treatment was 1.18. Hwang et al. studied the effects of winter and spring seasons and fine aerosols on lung obstruction in southern Taiwan from 2008 to 2010 [25]. They found that for each $10 \mathrm{mg} / \mathrm{m}^{3}$ increase in fine aerosols, the relative risk increased by $25 \%$.

\section{Conclusion}

Research in Taiwan and abroad have considered the impact of climate change transfer on diseases affecting the human cardiovascular and respiratory systems. They have reported that increasing temperatures and increasing frequency of extreme weather events, such as high temperature, low temperature and heat waves, lead to paroxysms of diseases ofthe cardiovascular and respiratory systems, and there exists a need for treatment of these diseases and deathsdue to these diseases. In addition, the interaction between meteorological conditions and air pollutants will increase the risk of these diseases.

In recent years, local county and city governments in Taiwan have grown aware to the behaviour of health-related risks against the background climate change. In this regard, these governments have drafted adaptability plans considering warming, uneven rainfall, heavy rainfall, typhoon intensity, sea level rise and air pollution. Among these six climate factors, warming and heavy rainfall are the two main climate factors for the adaptability plans for any county or city. Two other climate factors, namely, typhoon intensity and air pollution, have not yet been considered by mostcounties and cities. According to the AR5 report of the IPCC, the ground ozone concentrations at the end of the $21^{\text {st }}$ century may show an average increase of about $8 \mathrm{ppb}$; the localised high surface temperature chemical reactions and localised regional feedback will probably increase the concentration of ozone and fine aerosols [26]. In the current adaptability planning of cities and counties, the emphasis is on road dust and indoor and outdoor air quality improvement design. However, the impact of climate change on air quality will be severely affected by environmental changes, environmental policies, economic development and social activities. Hence, for future work, support of more research scientific evidence is necessary.

Finally, studies on climate change have generally only assessed the shocks and health risks in particular regions. These studies often underestimate the impact of climate change shocks. This is especially so because most researchers are specialised in particular fields and are often involved in multi-field research; during the evaluation process in such studies, less consideration is given to the effect of interactions between regions [27].

This article introduces the shocks of climate change and air quality on healthand deals with multiple disciplines. It aims to clarify that there are overlaps between the research fields of climate change, air quality and health, but that basic research in each field should continue,and through the exchange of information and knowledge and discussions among researchers, the fields should develop togetherin an orderly fashion. This will help establish new research fields through scientific research integration and breakthroughs in innovation. It is hoped that environmental management researchers can continue to work together to continuously strengthen cooperation and research in various fields and focus on the adaptability to climate change' to reduce the health hazards caused by shocks to humans [28-31]. 


\section{Disclosure statement}

No potential conflict of interest was reported by the authors.

\section{References}

1. Costello A, Abbas M, Allen A, Ball S, Bell S, et al. (2009) Managing the health effects of climate change, The Lancet Commissions 373: 1693-1733.

2. Executive Y(2011)DisasterPrevention WhitePaperin 2011. Retrieved fromhttps://www. cdprc.ey.gov.tw/DL.ashx? $\mathrm{u}=/$ Upload/UserFiles/100\%E5\%B9\%B4\%E7\%81\%BD\%E $5 \%$ AE\%B3\%E9\%98\%B2\%E6\%95\%91\%E7\%99\%BD\%E7\%9A\%AE\%E6\%9B\%B8. pdf.

3. Philip J Landrigan, Richard Fuller, Nereus J R Acosta, Olusoji Adeyi, Robert Arnold, et al. (2017) Pollution and health. The Lancet Commissions 391:462-512.

4. Ministry of Health and Welfare (2014) White Paper on Health Impact Policy in Response to Climate Change. Retrieved from https://www.mohw.gov.tw/dl-460952873d012-c2a1-4607-a127-afca00401129 html.

5. Langner J, Bergström R, Foltescu V (2005) Impact of climate change on surface ozone and deposition of Sulphur and nitrogen in Europe. Atmospheric Environment 39: 11291141 .

6. Racherla P N, Adams P J (2008) The response of surface ozone to climate change over the Eastern United States. Atmospheric Chemistry and Physics 8: 871-885.

7. Syri S, Karvosenoja N, Lehtilä A, Laurila T, Lindfors V, et al. (2002) Modeling the impacts of the Finnish climate strategy on air pollution, Atmospheric Environment 36: 3059-3069.

8. EPA US (2003) Environmental Protection Agency: Guidelines for developing an air quality (Ozone and $\mathrm{PM}_{2.5}$ ) forecasting program. EPA-456/R-03-002.

9. Sá E, Martins H, Ferreira J, Marta-Almeida M, Rocha A, et al. (2016) Climate change and pollutant emissions impacts on air quality in 2050 over Portugal. Atmospheric Environment 131: 209-224.

10. National Health Research Institutes (2017) Climate Change and Health, ISBN: 9789860533958.

11. Lin Y K, Wang Y C, Ho TJ, Lu CA (2013) Temperature effects on hospital admissions for kidney morbidity in Taiwan. Science of the Total Environment 443: 812-820.

12. Kim J, Shin J, Lim YH, Honda Y, Hashizume M, et al. (2016) Comprehensive approach to understand the association between diurnal temperature range and mortality in East Asia, Science of the Total Environment 1:313-321.

13. Kjellstrom T, Butler, A J, Lucas RM, Bonita R (2010) Public health impact of global heating due to climate change: potential effects on chronic non-communicable diseases, International Journal of Public Health 5: 97-103.

14. Vilkman S, Keistinen T, Tuuponen T, Kivelä SL (1996) Seasonal variation in hospital admissions for chronic obstructive pulmonary disease in Finland. Arctic Medica Research 55: 182-186.

15. Nguyen JL, Yang W, Ito K, Matte TD, Shaman J, et al. (2016) Seasonal influenza infections and cardiovascular disease mortality. JAMA Cardiology 1: 274-281.
16. Chung JY, Honda Y, Hong YC, Pan XC, Guo YL, et al. (2009) Ambient temperature and mortality: An international study in four capital cities of East Asia. Science of the Total Environment 408: 390-396.

17. Lin S, Luo M, Walker RJ, Liu X, Hwang SA, et al. (2009) Extreme high temperatures and hospital admissions for respiratory and cardiovascular diseases. Epidemiology 20 : 738-746.

18. Ostro B, Rauch S, Green R, Malig B, Basu R (2010) The effects of temperature and use of air conditioning on hospitalizations. American Journal of Epidemiology 172 : 1053-1061.

19. Chung Y, Lim YH, Honda Y, Guo YLL, Hashizume M, et al. (2015) Mortality related to extreme temperature for 15 cities in northeast Asia. Epidemiology 26: 255-262.

20. Huynen MM, Martens P, Schram D, Weijenberg MP, Kunst AE (2001)The impact of heat waves and cold spells on mortality rates in the Dutch population, Environmental Health Perspectives 109: 463-470.

21. Bobb JF, Obermeyer Z, Wang Y, Dominici F (2014) Cause-specific risk of hospita admission related to extreme heat in older adults. JAMA 312: 2659-2667.

22. Lin YK, Ho TJ, Wang YC (2011) Mortality risk associated with temperature and prolonged temperature extremes in elderly populations in Taiwan. Environmental Research 111: 1156-1163.

23. De Sario M, Katsouyanni K, Michelozzi P (2013) Climate change, extreme weather events, air pollution and respiratory health in Europe. European Respiratory Journal 42: 826-843.

24. Sheffield PE, Knowlton K, Carr JL, Kinney PL (2011) Modeling of regional climate change effects on ground-level ozone and childhood asthma. American Journal of Preventive Medicine 41: 251-257.

25. Hwang SL, Guo SE, Chi MC, Chou CT, Lin YC, et al. (2016) Association between atmospheric fine particulate matter and hospital admissions for chronic obstructive pulmonary disease in Southwestern Taiwan: A population-based study, International Journal of Environmental Research and Public Health 13: 1-9.

26. Inter-governmental Panel on Climate Change (2014) The Fifth Assessment Report.

27. Klein JT (2008) Evaluation of interdisciplinary and transdisciplinary research: A literature review, American Journal of Preventive Medicine 35: 116-123.

28. EPA US (2009) Environmental Protection Agency Assessment of the impacts of globa change on regional U.S. air quality: A synthesis of climate change impacts on groundlevel ozone, an interim report of the U.S. EPA Global Change Research Program, Washington, D.C.

29. World Health Organization. (2012) 10 facts on climate change and health. Retrieved from http://www.who.int/features/factfiles/climate_change/en/.

30. World Health Organization. (2012) Atlas of Health and Climate. Retrieved from http:// www.who.int/globalchange/publications/atlas/report/en/.

31. World Health Organization (2015) Heatwaves and Health: Guidance on WarningSystem Development. 